\title{
BREVES APONTAMENTOS SOBRE OS PROCEDIMENTOS DE COOPERAÇÃO INTERNACIONAL E O DIREITO PENAL ECONÔMICO: ANÁLISE DA ATUACÇÃO DO FUNDO MONETÁRIO INTERNACIONAL (FMI) NO COMBATE À LAVAGEM DE DINHEIRO
}

\author{
BRIEF NOTES ON INTERNATIONAL COOPERATION PROCEDURES AND THE \\ CRIMINAL ECONOMIC LAW: ANALYSIS OF THE INTERNATIONAL MONETARY \\ FUND PERFORMANCE IN THE FIGHT AGAINST MONEY LAUNDRY
}

Pablo Henrique Hübner de Lanna Costa

\begin{abstract}
Mestre em Proteção dos Direitos Fundamentais pela Universidade de Itaúna-MG. Graduado em Direito pela Escola Superior Dom Helder Câmara de Belo Horizonte-MG. Advogado e Consultor jurídico. E-mail: pablolanna@terra.com.br
\end{abstract}

\author{
Álisson Thiago de Assis Campos \\ Mestrando do PPGD - Mestrado em Proteção dos Direitos Fundamentais da Universidade \\ de Itaúna-MG. E-mail: alissonateticano@gmail.com
}

Deilton Ribeiro Brasil

Pós-Doutor em Direito pela Università degli Studi di Messina, Itália. Doutor em Direito pela UGF-RJ. Professor da Graduação e do PPGD - Mestrado em Direito Proteção dos Direitos Fundamentais e Graduação da Universidade de Itaúna-MG.

E-mail: deilton.ribeiro@terra.com.br

Recebido em: 31/08/2017

Aprovado em: 17/12/2017

RESUMO: A lavagem de dinheiro pode ser considerada como um conjunto de operações financeiras que busca injetar na economia do Estado os recursos, bens e serviços ligados à prática de infrações penais. Estes fatores fazem surgir a necessidade de cooperação internacional, com o objetivo de desenvolver procedimentos mais efetivos de combate ao branqueamento de capitais. Neste panorama se insere a atuação do Fundo Monetário Internacional, que no desempenho de suas atividades de supervisão e aconselhamento desenvolve atividades na matéria há mais de dezessete anos. O objetivo do presente estudo é realizar breves apontamentos sobre a lavagem de dinheiro e a cooperação internacional, assim como analisar a atuação do Fundo Monetário Internacional (FMI) no combate ao problema em questão. Para alcançar tal abordagem foi utilizado o método dedutivo, através da análise conceitual, normativa e jurisprudencial dos temas, para então abordar a atuação do FMI.

Palavras-chave: Lavagem de dinheiro. Cooperação Internacional. Fundo Monetário Internacional

ABSTRACT: Money laundering can be considered as a set of financial operations that seek to inject into the economy of the State resources, goods and services related to the practice of criminal offenses. These factors give rise to the need for international cooperation in order to 
develop more effective procedures to combat money laundering. This scope includes the activities of the International Monetary Fund, which in the performance of its supervisory and advisory activities has been active in this area for more than seventeen years. The objective of the present study is to make brief notes on money laundering and international cooperation, as well as to analyze the work of the International Monetary Fund (IMF) in combating the problem in question. In order to reach such an approach, the deductive method was used, through the conceptual, normative and jurisprudential analysis of the themes, to analyze the IMF's performance.

Keywords: Money Laundering. International Cooperation. International Monetary Fund

SUMARIO: Introdução; 1 Breves apontamentos sobre a lavagem de dinheiro; 1.1 A lavagem de dinheiro e o combate ao crime organizado; 2 Cooperação internacional em matéria penal; 3 A atuação do Fundo Monetário Internacional no combate à lavagem de dinheiro; 3.1 Impactos econômicos e monetários da lavagem de dinheiro; $3.2 \mathrm{O}$ programa de combate à lavagem de dinheiro desenvolvido pelo FMI; 3.3 Pontos positivos da atuação do FMI; Conclusão; Referências Bibliograficas.

\section{INTRODUÇÃO}

Praticada em âmbito doméstico e internacional, a lavagem de dinheiro consiste no ato de legitimar produtos e valores oriundos da prática de crime, injetando-os na economia do Estado com uma aparência legítima. Diante do forte impacto por ela ocasionado, sobretudo no âmbito da economia internacional, surgiu a necessidade de cooperação entre os Estados, com o objetivo de desenvolver procedimentos mais efetivos de combate e controle das transações comerciais suspeitas.

Nessa esteira, o Fundo Monetário Internacional (FMI) tem desempenhado um papel fundamental no combate à lavagem de dinheiro, sendo que há mais de dezessete anos vem alertando para situações que, por vezes, são ignoradas, demonstrando a profundidade e a gravidade dos problemas causados pela prática ilícita.

O presente artigo científico tem como propósito contribuir para o estudo da temática envolvendo a cooperação internacional em matéria penal, notadamente no que diz respeito aos crimes de lavagem de dinheiro, analisando a importância da atuação do Fundo Monetário Internacional (FMI) no combate ao problema em questão.

Para alcançar o objetivo acima estipulado, foi utilizado o método dedutivo, através da análise conceitual, normativa e jurisprudencial dos temas em discussão.

O trabalho foi dividido em tópicos, onde se buscou, primeiramente, conceituar a lavagem de dinheiro, situando-a no âmbito da criminalidade organizada. Posteriormente trabalhou-se a questão da cooperação internacional em matéria penal para, por fim, apresentar a atuação do Fundo Monetário Internacional no combate à lavagem de dinheiro, apontando os impactos da lavagem de dinheiro na economia e os pontos positivos de tal atuação.

Partindo de uma revisão de literatura calcada na releitura de doutrinadores que versam sobre a temática proposta e, ainda, mediante uma análise do arcabouço jurídico que incentiva o combate à lavagem de dinheiro e a cooperação internacional, pretende-se conceituar os aspectos relacionados ao tema. Nesse sentido, o levantamento bibliográfico fornecerá as bases teóricas necessárias para a elaboração adequada do trabalho, posto que informam os conceitos de ordem dogmática a serem utilizados. 


\section{BREVES APONTAMENTOS SOBRE A LAVAGEM DE DINHEIRO}

A lavagem de dinheiro consiste na prática de um conjunto de operações financeiras que buscam injetar na economia do Estado os recursos, bens e serviços ligados à prática de infrações penais. Como ensinam Pierpaolo Bottini e Gustavo Badaró, a lavagem de dinheiro trata "do movimento de afastamento dos bens de seu passado sujo, que se inicia com a ocultação simples e termina com sua introdução no circuito comercial ou financeiro, com aspecto legítimo" (2016, p. 29).

Em suma, lavar dinheiro consiste em legitimar produtos de crimes, mascarando a ilicitude de forma a permitir o ingresso do valor ilegal na economia nacional, dando-lhe uma aparência de legítima. Através da lavagem de dinheiro, o indivíduo converte a renda originária de uma atividade criminosa em fundos de origem aparentemente lícita, escondendo a existência de uma fonte ilegítima, disfarçando ou transformando essa renda para fazer com que ela pareça legal.

A origem do termo "Lavagem de Dinheiro" (Money Laudering) remonta à década de 30 do século passado, quando os mafiosos de Chicago, nos Estados Unidos, abriam lavanderias de fachada e as utilizavam para dar a aparência lícita ao produto que obtinham através de práticas criminosas. Por outro lado, a primeira vez em que a expressão foi empregada em um processo judicial americano foi em 1982, a partir de quando se popularizou na literatura jurídica e em normas ao redor do mundo (BADARÓ; BOTTINI, 2016, p. 29)

Com o passar dos anos, as técnicas de inserção de dinheiro ilícito na economia foram se ampliando e tornando-se cada vez mais complexas. Assim, para alcançar seus objetivos, os agentes lançam mão de múltiplas transações para ocultar a origem dos ativos financeiros, dissimulando a ilicitude e buscando o distanciamento do dinheiro do crime que o originou, culminando na reinserção do capital na economia formal.

Nessa esteira Gustavo Badaró e Pierpaolo Bottini (2016, p. 32) ensinam que o processo de branqueamento de capitais é composto, minimamente, de três fases distintas, que muito embora sejam dinâmicas e possam se sobrepor - o que torna difícil a identificação no caso concreto - caracterizam-se pela existência de ocultação, dissimulação e integração dos bens à economia.

A ocultação (placement), fase inicial da lavagem de dinheiro, pode ser observada por meio do movimento inicial para esconder o valor auferido de maneira criminosa, distanciando-o de sua origem.

Algumas das formas mais corriqueiras de ocultação de patrimônio ilícito são o fracionamento dos valores em quantias menores que não chamam a atenção das autoridades (surfing ou structuring), seu depósito em conta de terceiros (os denominados "laranjas") e, ainda, a transferência dos valores para paraísos fiscais que dificultem a identificação dos bens e de seus proprietários.

Por sua vez, a dissimulação (layering) pode ser observada através de diversas transações que contribuem para "apagar o rastro" do dinheiro sujo, contribuindo para afastar os valores de sua origem ilícita. Pierpaolo Bottini e Gustavo Badaró identificam como exemplos de dissimulação:

o envio do dinheiro já convertido em moeda estrangeira para o exterior via cabo para contas de terceiros ou de empresas das quais o agente não seja beneficiário ostensivo, o repasse dos valores convertidos em cheque de viagem ao portador com troca em outro país, as transferências eletrônicas não oficiais, dentre tantas outras. (2016, p. 33)

Por fim, a última fase da lavagem de dinheiro caracteriza-se pela integração do valor ilícito à economia nacional (integration), com aparência lícita. Nessa fase, os valores já Revista de Direito Brasileira | São Paulo, SP | v. 19 | n. 8 | p. 122 - 140 |Jan./Abr. 2018 
dissimulados "são reciclados em simulações de negócios lícitos, como transações de importação/exportação simuladas, com preços excedentes ou subfaturados, compra e venda de imóveis com valores diferentes daqueles de mercado, ou em empréstimos de regresso (loonback)". (BADARÓ; BOTTINI, 2016, p. 33)

Merece destaque o fato de que "o processo de lavagem de dinheiro tem como antecedente necessário a prática de uma infração penal - momento de origem do recurso ilícito e se inicia com a ocultação dos valores auferidos." (BADARÓ; BOTTINI, 2016, p. 31). Entretanto, que a legislação brasileira não determina que todos os ciclos estejam completos para que haja a caracterização do crime de lavagem de dinheiro. Basta a ocorrência de ocultação para que o delito de caracterize. Por outro lado,

ainda que o delito esteja consumado desde a fase inicial de ocultação, há um elemento subjetivo que permeia todas as etapas do crime em tela: a vontade de lavar o capital, de reinseri-lo na economia formal com aparência de licitude. Ainda que no plano objetivo seja suficiente a mera ocultação dos bens para a caracterização da lavagem de dinheiro, na esfera subjetiva sempre será necessária a intenção de reciclar os bens, o desejo de completar o ciclo de reciclagem. (BADARÓ; BOTTINI, 2016, p. 33)

Nessa ótica, é indiscutível que o elemento subjetivo necessário à caracterização do crime de lavagem de dinheiro é o dolo, inexistindo previsão legal para punição a título de culpa. Surge, aí, uma nova discussão, acerca da (in)admissibilidade do dolo eventual para caracterização do delito.

Embora seja questão extremamente controvertida no Direito Penal, é importante lembrar que no julgamento da Ação Penal 470 (popularmente conhecida como mensalão) o ministro Celso de Mello, do STF, entendeu ser possível o dolo eventual em crimes de lavagem de capitais com suporte na teoria da cegueira deliberada, isto é, quando o agente finge não perceber determinada situação de ilicitude para alcançar a vantagem pretendida.

A lavagem de dinheiro gera custos sociais, na medida em que permite gera a sensação de que o delito vale a pena, posto que permite que criminosos se utilizem das vantagens ilícitas recebidas e expandam suas operações. Não fosse isso, ela coloca em risco a integridade do mercado financeiro e a concorrência privada, propondo desafios que requerem dos Estados a adoção de medidas eficazes para o combate à criminalidade.

A necessidade de combate à lavagem de dinheiro decorre da necessidade de impedir que a prática possa comprometer a estabilidade financeira nacional, facilitando atividades perniciosas e que possam degradar as estruturas do próprio Estado Democrático de Direito.

Num momento de rápido desenvolvimento tecnológico e globalizado, o branqueamento de capitais pode comprometer a estabilidade financeira nacional porque facilita atividades criminosas que são altamente prejudiciais para a sociedade. Nesse sentido, o COAF afirma que o branqueamento de capitais é uma das formas mais eficazes para criminosos promoverem seus interesses secretos - (MATSUDA, 2007, p.8) (tradução livre) $)^{1}$

1 In a time of fast technological and globalizing development, money laundering can compromise national financial stability because it facilitates criminal activities that are highly damaging to society. As regards, COAF states that money laundering is one of the most effective ways for criminals to safeguard and promote their covert interests. (MATSUDA, 2007, p.8). 
Infere-se, daí, uma íntima ligação entre a lavagem de dinheiro e o crime organizado, sendo que o combate ao branqueamento de capitais, necessariamente, gera impacto na criminalidade organizada ao redor do mundo, conforme será abordado a seguir.

\subsection{A lavagem de dinheiro e o combate ao crime organizado}

A preocupação com a implementação de técnicas heterodoxas no combate à lavagem de dinheiro decorre de uma percepção de que tal prática delituosa guarda estreita relação com o crime organizado e, até mesmo por isso, vem evoluindo e adotando comportamentos complexos que buscam ludibriar as forças de investigação tradicionais.

Com efeito, este tipo de criminalidade abarca algo diferente da microcriminalidade (ou criminalidade tradicional) porque são praticados por pessoas de um padrão social e econômico mais elevado, que valem-se de uma profissão aparentemente lícita que exercem com evidente caráter abusivo.

Foi no final da década de 80 do século passado que a lavagem de dinheiro passou a ser analisada com maior atenção por parte da comunidade internacional, dada a força e capacidade de organização de vários setores ligados ao crime organizado, notadamente ao tráfico internacional de drogas. Nesse sentido, a criminalização do ato de lavagem de dinheiro parte da ideia de que uma das melhores formas de se combater o crime organizado é, justamente, bloquear o financiamento das práticas ilícitas.

A forte ligação entre os crimes de lavagem de dinheiro e o crime organizado acabou tornando a prática mais expressiva e sofisticada. Por essa razão, uma das formas mais importantes de combate ao crime organizado é, justamente, esclarecer as técnicas utilizadas para lavagem de dinheiro, impedindo a perpetuação do financiamento da criminalidade. É nesse sentido que Mário Zanchetti ensina que combater a lavagem de dinheiro é atacar o "calcanhar de Aquiles" da criminalidade organizada (2001, p. 32-36).

Uma das características da lavagem de dinheiro é o investimento em atividades lícitas que possibilitem o "branqueamento" do capital obtido a partir da prática do crime. Isso acaba dificultando o combate e impondo a utilização de mecanismos diferenciados de combate à criminalidade, que segundo Fausto de Sanctis seriam justificados pelo caráter de emergência na luta contra a prática de crimes que corroem os alicerces do próprio Estado de Direito (2015, p. 30).

Por essa razão, inclusive, o Grupo de Ação Financeira Internacional em Lavagem de Dinheiro - $\mathrm{GAFI}^{2}$ recomenda que as autoridades se utilizem de técnicas especiais de investigação, conforme exposto na recomendação n. 31, in verbis:

Durante o curso de investigações de lavagem de dinheiro, de crimes antecedentes e de financiamento do terrorismo, as autoridades competentes deveriam ter acesso a todos os documentos e informações necessários para as investigações, bem como para as ações penais e outras ações a elas relacionadas. Esses poderes deveriam incluir o poder de adotar medidas compulsórias para a requisição de registros mantidos por instituições financeiras, APNFDs e outras pessoas físicas ou jurídicas, bem como para a busca de pessoas e propriedades, para a tomada de declarações de testemunhas, e para a busca e obtenção de provas. Os países deveriam assegurar que as autoridades competentes ao conduzirem investigação tenham acesso a uma grande variedade de técnicas investigativas adequadas às investigações de lavagem de dinheiro, crimes antecedentes e financiamento do terrorismo. Tais técnicas incluem: operações encobertas, interceptação de comunicações, acesso a sistemas computacionais e

2 Por vezes a denominação aparece escrita na versão francesa (Groupe d'Action Financière sur le Blanchiment de Capitaux - GAFI) ou inglesa (Financial Action Task Force on Money Laundering - FATF)

Revista de Direito Brasileira | São Paulo, SP | v. 19 | n. 8 | p. 122 - 140 |Jan./Abr. 2018 
entrega controlada. Além disso, os países deveriam possuir mecanismos efetivos para identificar rapidamente se pessoas físicas ou jurídicas são titulares ou controlam contas. Deveriam também possuir mecanismos para garantir que as autoridades competentes tenham algum procedimento para identificar ativos sem notificação prévia do proprietário. Durante as investigações de lavagem de dinheiro, crimes antecedentes e financiamento do terrorismo, as autoridades competentes deveriam poder solicitar quaisquer informações relevantes à UIF.

Em se tratando de grandes organizações criminosas, a utilização dos métodos tradicionais de repressão (como a prisão de grandes traficantes, por exemplo) acaba surtindo pouco efeito. Isto ocorre porque os postos na cadeia de comando da organização podem ser exercidos de dentro da prisão ou serem facilmente substituídos por outros indivíduos que dão continuidade aos ilícitos, retroalimentando a prática criminosa. (PITOMBO, 2003, p. 28)

No aspecto legislativo, começaram a surgir leis tipificando a ocultação e dissimulação de bens decorrentes de práticas criminosas. Por outro lado, no âmbito da política criminal propriamente dita, ao lado do aparato policial de repressão,

surgiram unidades de inteligência financeira voltadas ao armazenamento e tratamento de informações capazes de identificar o dinheiro sujo, oriundo de atividades criminosas, e responsável pela manutenção das estruturas de poder ilegal. (BADARÓ; BOTTINI, 2016, p. 30).

No caso brasileiro, como bem elucida Kai Ambos, as propostas legais para criminalização da lavagem de dinheiro seguiram

o clássico princípio da justiça penal universal, mediante tratados e convenções, como estratégia de uma política criminal transnacional, observando-se que, com a subscrição de tais tratados e convenções, cada país subscritor se compromete a elaborar normas que viabilizem a consecução dos objetivos dos instrumentos internacionais no plano interno. E no Brasil, já pelo teor do Projeto que definia o crime de lavagem de dinheiro, identifica-se a influência das disposições normativas internacionais, tendo em vista que a própria designação "lavagem de dinheiro" passou por uma análise desde a perspectiva internacional, visando melhor adequação no contexto social.(2007, p. 49)

Dessa forma, o artigo $1^{\circ}$ da Lei $\mathrm{n}^{\circ}$ 9.613, de 1998 tratou de definir a lavagem de dinheiro como sendo qualquer prática tendente a "ocultar ou dissimular a natureza, origem, localização, disposição, movimentação ou propriedade de bens, direitos ou valores provenientes, direta ou indiretamente, de infração penal".

Originariamente, somente alguns crimes específicos poderiam dar ensejo ao crime de lavagem de dinheiro, os quais eram definidos em rol taxativo pela lei 9.613/98. A ampliação desse conceito, entretanto, foi trazida em 2012, quando passou a admitir que qualquer infração penal pudesse anteceder o crime de lavagem de dinheiro.

Outro aspecto relevante da Lei 9.613/98 foi que, para além de armas, viaturas e coletes, os Estados passaram a se valer de relatórios, dados e dossiês para enfrentar a criminalidade organizada e desmantelar as associações criminosas. (BADARÓ; BOTTINI, 2016, p. 30). Nesse sentido, a criação do Conselho de Controle de Atividades Financeiras (COAF) merece relevante destaque.

Instalado no o âmbito do Ministério da Fazenda, o Conselho de Controle de Atividades Financeiras - COAF funciona como uma espécie de unidade de inteligência financeira nacional. Previsto no artigo 14 da Lei 9.613, o COAF foi criado "com a finalidade de disciplinar, aplicar 
penas administrativas, receber, examinar e identificar as ocorrências suspeitas de atividades ilícitas previstas nesta Lei”.

A composição do COAF é prevista pelo artigo 16 da lei 9.613/98, que prevê que o ingresso no referido conselho se dê por meio de

servidores públicos de reputação ilibada e reconhecida competência, designados em ato do Ministro de Estado da Fazenda, dentre os integrantes do quadro de pessoal efetivo do Banco Central do Brasil, da Comissão de Valores Mobiliários, da Superintendência de Seguros Privados, da Procuradoria-Geral da Fazenda Nacional, da Secretaria da Receita Federal do Brasil, da Agência Brasileira de Inteligência, do Ministério das Relações Exteriores, do Ministério da Justiça, do Departamento de Polícia Federal, do Ministério da Previdência Social e da Controladoria-Geral da União, atendendo à indicação dos respectivos Ministros de Estado.

Vale lembrar, entretanto, que as características transnacionais das organizações criminosas e, consequentemente, da lavagem de dinheiro, dificulta a implementação de políticas isoladas de combate a tais práticas. Nesse sentido, torna-se fundamental o desenvolvimento de políticas de cooperação internacional que busquem harmonizar as normas que tratam sobre o tema ao redor do mundo, compatibilizando princípios e facilitando o acesso de dados e a realização de diligências.

\section{COOPERAÇÃO INTERNACIONAL EM MATÉRIA PENAL}

A palavra "cooperação" pressupõe a existência de uma colaboração, isto é, um trabalho conjunto realizado entre as partes para a consecução de um objetivo comum. No âmbito do Direito, sempre que uma cooperação tiver reflexos jurídicos, será denominada cooperação jurídica, podendo se estabelecer, inclusive, entre Estados soberanos. Nessa hipótese, será classificada como "cooperação jurídica internacional".

Conforme ensina Ricardo P. Mendes da Silva, a "expressão 'cooperação jurídica internacional' decorre da ideia de que a efetividade da jurisdição, nacional ou estrangeira, pode depender do intercâmbio não apenas entre órgãos judiciais, mas também entre órgãos judiciais e administrativos, de estados distintos." (2006, p. 798)

$\mathrm{O}$ avanço da tecnologia e a globalização do sistema financeiro ocasionou um aumento na complexidade dos casos envolvendo lavagem de dinheiro, fazendo com que a prática fosse exercida no âmbito internacional. Nesse sentido foi a advertência feita em 2007 pelo Departamento de Justiça dos Estados Unidos, através do seu chefe da Seção de recuperação de ativos e lavagem de dinheiro (Asset Forfeiture and Money Laundering Section), Richard Weber:

Os sistemas financeiros modernos permitem que os criminosos transfiram milhões de dólares instantaneamente, por meio de computadores pessoais e via satélite. O dinheiro é lavado através de casas de câmbio, corretoras de ações, negociantes de ouro, casinos, concessionárias de automóveis, companhias de seguros, empresas comerciais e outros sistemas sofisticados. As instalações bancárias privadas, as operações bancárias offshore, as corporações, as zonas de livre comércio, os sistemas de transmissão e o financiamento comercial têm a capacidade de mascarar atividades ilegais. A escolha dos meios de lavagem de dinheiro pelo criminoso é limitada apenas pela sua criatividade. Em última análise, esse dinheiro lavado flui para os sistemas financeiros globais, onde pode prejudicar economias e moedas nacionais. Os grupos criminosos organizados 
transcendem as fronteiras nacionais e ampliam sua influência para áreas do mundo distantes dos países de origem. A erosão gradual dos controles de fronteiras nos países da Europa não só contribui para a livre circulação do comércio e negócio, mas também aumenta a ameaça de crimes transfronteiriços. Esta internacionalização do crime torna essencial a partilha, a cotação e a análise da informação, entre e dentro dos governos. (2007, p. 01)

A sofisticação dos métodos implementados para mascarar a origem ilícita dos valores oriundos dos crimes praticados ao redor do mundo e a consequente preocupação das autoridades em adotar medidas eficazes para conter o avanço de tal prática deu ensejo à criação de um panorama normativo que possibilite a cooperação jurídica internacional.

Em suma, há um esforço mundial para reprimir a reciclagem de capitais, por meio do desenvolvimento de políticas criminais de repressão e de mecanismos de controle das atividades nos setores sensíveis a tais práticas. A dinâmica dos processos de lavagem de dinheiro - e a criatividade dos agentes responsáveis por sua realização - acaba por gerar, diuturnamente, novas estratégias de mascaramento de capital sujo, com subterfúgios que dificultam as ações de investigação e rastreamento. Por isso, impõe-se às autoridades públicas, um constante acompanhamento das novas formas de escamoteamento de bens, para aprimorar a identificação e repressão do comportamento em tela. Nesse sentido, foram instituídos grupos de especialistas e de autoridades públicas com atribuições de monitorar constantemente atividades de lavagem de dinheiro, e suas técnicas mais diversas, para a proposição de novos instrumentos de prevenção e repressão à prática. (BADARÓ; BOTTINI, 2016, p. 38)

Conforme ensina Antônio Sérgio A. de M. Pitombo, desde o final dos anos 80 foram criados vários documentos supranacionais no intuito de intensificar o combate à lavagem de dinheiro (2003, p. 44), sendo que esse esforço internacional gerou forte impacto no desenvolvimento de políticas de combate a tal prática. A consequência disso foi produção de normas similares ao redor do mundo, o que acabou facilitando a cooperação entre os Estados.

A esse respeito, três documentos internacionais merecem especial destaque, por possibilitarem o aprimoramento da política de combate à lavagem de dinheiro ao redor do mundo. São eles, a Convenção de Viena de 1988 (Convenção Contra o Tráfico Ilícito de Entorpecentes e Substâncias Psicotrópicas), Convenção de Palermo de 2000 (Convenção das Nações Unidas contra o Crime Organizado Transnacional) e a Convenção de Mérida de 2003 (Convenção das Nações Unidas contra a Corrupção).

Por terem sido formalmente incorporadas ao ordenamento jurídico brasileiro, as convenções mencionadas auxiliaram na construção de um marco legal sobre lavagem de dinheiro e influenciam, diretamente, nas questões hermenêuticas relativas às normas de combate ao crime. Torna-se, portanto, essencial compreender cada uma delas a fim de entender como se dá a sistemática global de proteção dos Estados contra a lavagem de dinheiro.

A Convenção de Viena de 1988 apresentou uma definição inicial sobre o que seria o crime de lavagem de dinheiro no âmbito do narcotráfico, convencionando que os países que ratificassem o tratado envidariam esforços no sentido de criar um tipo penal com a finalidade de responsabilizar o agente que ocultasse bens ou valores oriundos do tráfico internacional de drogas. Pioneira nessa temática, essa convenção internacional significou melhorias para a cooperação internacional, propondo uma ação conjunta como meio para extinguir atividades internacionais do delito, tendo sido incorporada pelo Brasil em 1991, através do Decreto n. 154.

A Convenção de Viena (20.12.1988) inaugura a previsão de lavagem de dinheiro em documentos do gênero. O objetivo central do diploma é o combate ao tráfico 
de drogas. A sofisticação das organizações criminosas voltadas para a prática desse delito e a ousadia de sua atuação no âmbito internacional chamou a atenção de representantes de diversos países e ensejou a elaboração da normativa conjunta. Dentre as estratégias previstas na Convenção para o combate ao tráfico de drogas, menciona-se a importância de "privar as pessoas dedicadas ao tráfico ilícito do produto de suas atividades criminosas e eliminar, assim, o principal incentivo a essa atividade". Para isso, o diploma prevê que os países-parte devem caracterizar como ilícitos penais a conversão ou transferência de bens, com o conhecimento de que tais bens são procedentes do tráfico ilícito de entorpecentes com o objetivo de ocultar ou encobrir a origem ilícita dos bens, ou de ajudar a qualquer pessoa que participe na prática do delito a fugir das consequências jurídicas de seus atos. Ainda que a Convenção não faça uso expresso do termo "lavagem de dinheiro", é inegável que o preceito destacado trata desse processo criminoso, mesmo que em caráter restrito, uma vez que o único crime antecedente capaz de gerar bens passíveis de reciclagem nos termos da Convenção - é o tráfico de drogas. (BADARÓ; BOTTINI, 2016, p. 36-37)

A Convenção de Palermo, por sua vez, ampliou o objeto material do delito de lavagem de dinheiro, na medida em que possibilitou que outros tipos penais pudessem ser admitidos como delitos antecedentes, o que antes estava restrito ao tráfico de drogas. Incorporada pelo Brasil no ano de 2004, através do decreto n. 5.015/04, a referida convenção impôs algumas inovações na medida em que apresentou novos mecanismos de prevenção à lavagem de dinheiro.

A Convenção de Palermo vai além da Convenção de Viena ao indicar que diversos crimes - além do tráfico de drogas - podem originar bens passíveis de lavagem de dinheiro. O texto aponta que o delito decorre da "mais ampla gama possível de infrações principais" ou "infrações graves" (artigo 6, 2, a), conceituando-as como atos que constituam infrações puníveis com uma pena de privação de liberdade cujo máximo não seja inferior a quatro anos ou com pena superior (artigo 2) ou praticadas por meio de organização criminosa (artigo 5) ou aquelas relacionadas à corrupção (artigo 8) ou os crimes de obstrução da Justiça (artigo 23). A Convenção de Palermo ainda prevê medidas de regulação e controle de bancos e outras instituições sensíveis à lavagem de dinheiro com o escopo de conhecer seus usuários e eventuais operações suspeitas por eles praticadas. (BADARÓ; BOTTINI, 2016, p. 37)

Por sua vez, a convenção de Mérida foi incorporada ao ordenamento jurídico brasileiro no ano de 2006, através do Decreto n. 5.687/06, e incentivou a cooperação internacional para investigação dos crimes de lavagem de dinheiro.

[...] a Convenção de Mérida, adotada pela ONU em 2003 e promulgada pelo Brasil em 31 de janeiro de 2006 (Decreto 5.687), tem por objetivo específico o combate à corrupção. Dedica seu artigo 14 à lavagem de dinheiro, impondo aos Estados Parte a instituição de rígidos controles administrativos sobre a atuação de setores sensíveis - instituições financeiras e não financeiras usadas frequentemente para lavagem de dinheiro - e estabelecendo medidas de fomento à cooperação internacional. (BADARÓ; BOTTINI, 2016, p. 37)

Para além dos tratados acima elencados, torna-se necessário mencionar que o Brasil é signatário de outras normas internacionais que possibilitam a cooperação jurídica no âmbito internacional. 
No sistema de tratados internacionais do MERCOSUL, por exemplo, o Brasil assinou o Acordo de Extradição entre os Estados Partes do MERCOSUL (Decreto 4.975/04), o Protocolo de Medidas Cautelares do MERCOSUL (Decreto 2.626/98) e o Protocolo de Assistência Jurídica Mútua em Assuntos Penais do MERCOSUL (Decreto 3.468/00). Já no âmbito interamericano o país é signatário da Convenção Interamericana sobre o Cumprimento de Sentenças Penais no Exterior (Decreto 5.919/06) e da Convenção Interamericana sobre Assistência Mútua em Matéria Penal e seu Protocolo Facultativo (Decreto 6.340/08)

A necessidade de criação de tratados que possibilitem a cooperação jurídica internacional em matéria penal decorre dos entraves ocasionados pela soberania estatal, diante da impossibilidade de um Estado exercer o jus puniendi fora do seu território. Conforme lembra Eduardo Felipe P. Matias, duas questões relevantes devem ser lembradas, sendo que a primeira delas está relacionada "com a consciência dos Estados quanto ao fato de que não são autossuficientes, de que o isolamento representa um retrocesso e de que o crescimento está vinculado à cooperação. O segundo fator é a coexistência de múltiplos Estados independentes." (2006, p. 206).

Diante da intensificação das relações internacionais e da necessidade de se adequar às novas realidades impostas pelo dinamismo da globalização, os mecanismos de auxílio tem se tornado um instrumento eficaz através do qual os Estados se ajudam mutuamente para tratar de questões de interesse Penal e Processual Penal.

No caso brasileiro, a legislação interna prevê que a cooperação jurídica na seara penal seja realizada através de institutos tradicionais (como a extradição, a homologação de sentença estrangeira ${ }^{3}$ e as cartas rogatórias ${ }^{4}$ ) ou mesmo através de outros mecanismos como "auxílio direto" ou algum outro instrumento que venha a ser previsto em acordos internacionais.

Conforme ensina Paulo Henrique Gonçalves Portela, a cooperação jurídica internacional em matéria penal é pautada pelo princípio da dupla incriminação, de forma que o ato ilícito que fundamenta o pedido de cooperação deve ser tipificado pela legislação dos dois estados polos da relação cooperacional. Não obstante, o autor assevera que o referido mandamento de otimização pode ser mitigado em nome do princípio da cooperação entre os povos para o progresso da humanidade, conforme previsão já estabelecida no Tratado de Assistência Mútua em Matéria Penal entre o Governo da República Federativa do Brasil e o Governo do Canadá (Decreto 6.747/09) e no Acordo de Cooperação e Auxílio Jurídico Mútuo em Matéria Penal entre a República Federativa do Brasil e o Reino da Espanha (Decreto 6.681/08). (PORTELA, 2017, p. 553-554)

As formas de cooperação internacional são diversas e os mecanismos para tratar dos bens provenientes de atividades ilícitas podem variar desde a mera apreensão e confisco, até sua restituição às vítimas. Em relação às pessoas, por outro lado, há possibilidade de transferência de presos e extradição, ressalvando-se, ainda, a possibilidade de aplicação de medidas que visem à proteção das vítimas, testemunhas e delatores que se encontrem envolvidos com os casos em investigação, além de outras ações preventivas (PORTELA, 2016, p. 557).

Somente a título de exemplo, vale mencionar que nos casos envolvendo confisco, o Superior Tribunal de Justiça entendeu ser possível a homologação de sentença estrangeira em que se tenha determinado o perdimento de imóvel situado no Brasil caso seja produto do crime de lavagem de dinheiro:

HOMOLOGAÇÃO DE SENTENÇA ESTRANGEIRA. CONFISCO DE BENS IMÓVEIS, PRODUTOS DE ATIVIDADE CRIMINOSA, SITUADOS NO BRASIL. COOPERAÇÃO INTERNACIONAL. CONVENÇÃO DE

3 Artigos 787 a 790 do Código de Processo Penal e Artigo 105, I, “i” da Constituição Federal.

4 Artigos 783 a 786 do Código de Processo Penal e Artigo 36 do Código de Processo Civil.

5 Artigos 28 a 34 do Código de Processo Civil.

Revista de Direito Brasileira | São Paulo, SP | v. 19 | n. 8 | p. 122 - 140 |Jan./Abr. 2018 
PALERMO. CRIME TIPIFICADO NAS LEGISLAÇÕES ESTRANGEIRA E NACIONAL. EFEITO DA CONDENAÇÃO PREVISTO TAMBÉM NA LEI BRASILEIRA. AUSÊNCIA DE OFENSA À SOBERANIA NACIONAL. REQUISITOS PREENCHIDOS. HOMOLOGAÇÃO DEFERIDA. 1. A sentença homologanda determinou a perda de bens imóveis da Requerida, situados no Brasil, pois foram objeto do crime de lavagem de dinheiro a que ela foi condenada. 2. Nos termos do artigo $9^{\circ}$, inciso I, do Código Penal, "A sentença estrangeira, quando a aplicação da lei brasileira produz na espécie as mesmas consequências, pode ser homologada no Brasil para" "obrigar o condenado à reparação do dano, a restituições e a outros efeitos civis". É o que ocorre no caso, pois também a lei brasileira prevê a possibilidade de perda, em favor da União, ressalvado o direito do lesado ou de terceiro de boa-fé, do produto do crime, como um dos efeitos da condenação (artigo 91, inciso II, alínea $b$, do Código Penal). 3. Não há ofensa à soberania nacional, pois a sentença não tratou especificamente sobre a situação dos bens imóveis, sobre a sua titularidade, mas sim sobre os efeitos civis de uma condenação penal, determinando o perdimento de bens que foram objeto de crime de lavagem de capitais. $\mathrm{O}$ confisco dos bens, além de ser previsto na legislação interna, tem suporte na Convenção das Nações Unidas contra o Crime Organizado Transnacional (Convenção de Palermo), promulgada pelo Decreto $\mathrm{n}^{\circ}{ }^{\circ}$ 5.015/2004, de que também é signatária a Finlândia. 4. Os bens imóveis confiscados não serão transferidos para a titularidade do país interessado, mas serão levados a hasta pública, nos termos do artigo 133 do Código de Processo Penal. 5. Pedido de homologação deferido. (SUPERIOR TRIBUNAL DE JUSTIÇA, 2016)

Muito embora as vias diplomáticas sejam os meios tradicionais para os pedidos de auxílio entre Estados, a complexidade de algumas questões envolvendo a cooperação jurídica internacional em matéria penal vem exigindo a criação de uma estrutura bem organizada para execução de seus fins. No caso brasileiro, é a cooperação internacional conta com o apoio das denominadas "Autoridades Centrais":

que são órgãos das estruturas governamentais dos Estados, indicados por estes, que concentrarão o tratamento das demandas relativas ao auxílio que os entes estatais prestam entre si não só no combate ao crime, mas também em outras áreas do Direito (inclusive no campo cível). Para a Procuradoria Geral da República, a autoridade central é "a autoridade designada para gerenciar o envio e o recebimento de pedidos de auxílio jurídico, adequando-os e os remetendo às respectivas autoridades nacionais e estrangeiras competentes. No Brasil, a autoridade central examina os pedidos ativos e passivos, sugerindo adequações, exercendo uma sorte de juízo de admissibilidade administrativo, tendente a acelerar e melhorar a qualidade dos resultados da cooperação. Já para o Ministério da Justiça, a autoridade central é "um conceito consagrado no Direito Internacional e visa a determinar um ponto unificado de contato para a tramitação dos pedidos de cooperação jurídica internacional, com vistas à efetividade e à celeridade desses pedidos. A principal função da Autoridade Central é buscar maior celeridade e efetividade aos pedidos de cooperação jurídica internacional penal ou civis. Para isso, recebe, analisa, adequa, transmite e acompanha o cumprimento dos pedidos junto às autoridades estrangeiras" acrescentando que "Essa análise leva em conta a legislação nacional e os tratados vigentes, bem como normativos, práticas e costumes nacionais e internacionais. (PORTELA, 2016, p. 567-568) 
No caso brasileiro a Autoridade Central mais relevante é o Departamento de Recuperação de Ativos e Cooperação Jurídica Internacional (DRCI) vinculado à Secretaria Nacional de Justiça e, consequentemente, ao Ministério da Justiça (artigo 11, IV do Decreto 6.061/07). Não obstante, também a Procuradoria Geral da República e a Secretaria de Direitos Humanos da Presidência da República vêm atuando como autoridades centrais em razão de determinações constantes em tratados internacionais, tais como o Tratado de Auxílio Mútuo em Matéria Penal entre o Governo da República Portuguesa e o Governo da República Federativa do Brasil de 1991 (Decreto 1.320/94), Tratado de Assistência Mútua em Matéria Penal entre o Governo da República Federativa do Brasil e o Governo do Canadá (Decreto 6.747/09), dentre outros.

Por fim, vale destacar a existência de redes de cooperação entre o Ministério Público e órgãos dos Poderes Executivo e Judiciário, buscando uma maior integração entre as estruturas estatais, buscando solucionar eventuais dificuldades decorrentes dos processos de cooperação.

Conforme lembra Paulo Henrique Gonçalves Portela, o Brasil faz parte de algumas redes de cooperação internacional, tais como a Rede Iberoamericana de Cooperação Judicial (IberRED/IberRede), a Rede Hemisférica de Intercâmbio de Informações para o Auxílio Jurídico Mútuo em Matéria Penal e de Extradição e a Rede de Cooperação Jurídica e Judiciária Internacional dos Países de Língua Portuguesa (Rede Judiciária da CPLP).

Todas elas buscam facilitar o acesso a informações, viabilizando o cumprimento de procedimentos e prazos específicos de cada Estado, notabilizando-se pelos "pontos de contato nacionais", que atuam de forma a permitir intercâmbio de informações por meio de contatos informais.

\section{A ATUAÇÃO DO FUNDO MONETÁRIO INTERNACIONAL NO COMBATE À LAVAGEM DE DINHEIRO}

Torna-se evidente o quão nociva é a lavagem de dinheiro, não somente em razão da "teia" de ilícitos que circundam todo o procedimento, mas também pelos efeitos perversos que causa aos sistemas econômicos e monetários, tanto a nível doméstico quanto global.

Sendo assim, o objetivo do presente tópico é analisar alguns dos efeitos monetários e econômicos - especialmente com relação ao balanço de pagamentos, tópico de expertise do FMI - causados pela lavagem de dinheiro, de forma a explicitar como e porque o processo de lavagem de dinheiro, silencioso na maior parte das vezes, gera efeitos extremamente perversos às economias nacionais e também à economia global.

O resguardo da saúde e equilíbrio econômico global é um dos objetivos e funções do Fundo Monetário Internacional (FMI), razão pela qual será também analisado como o Fundo enfrenta a lavagem de dinheiro, quais são os mecanismos que utiliza para combater o problema, bem como os resultados que a iniciativa alcançou ao longo dos anos.

A inclusão do tema lavagem de dinheiro na atuação do FMI ocorreu há dezessete anos, tendo o auxílio do FMI sido utilizado por diversos países e de maneiras distintas, adaptando a iniciativa às reais necessidades de cada nação, sempre com o objetivo central bem delimitado, resguardar o equilíbrio econômico e, simultaneamente, combater os ilícitos que circundam a lavagem de dinheiro.

Trata-se, então, de matéria de extrema relevância e complexidade, uma vez que será estabelecida uma clara conexão entre a economia e o direito - ciências sociais aplicadas - de fundamental importância para uma plena compreensão do fenômeno, seus reais efeitos e melhores maneiras de enfrentamento. 


\subsection{Impactos econômicos e monetários da lavagem de dinheiro}

Serão tratados aqui alguns dos principais desdobramentos econômicos relacionados à lavagem de dinheiro, cuja compreensão permitirá um entendimento mais amplo do fenômeno e as razões pelas quais deve ser combatido com extrema seriedade.

O Fundo Monetário Internacional desenvolve suas atividades baseado em uma relação próxima com seus membros, permitindo o desenho, análise e implementação de programas especificamente destinados às necessidades particulares de cada economia. Para desenvolver este trabalho, o Fundo utiliza-se com muita frequência e atenção da análise do balanço de pagamentos. Este instrumento permite a verificação de uma série de indicadores econômicos e financeiros, servindo como uma espécie de "termômetro" para a atuação do Fundo, a qual aborda com muita profundidade todos os problemas relacionados ao balanço, em seus mais diversos aspectos.

Em se tratando de lavagem de dinheiro, a abordagem não foi diferente, a verificação e análise dos efeitos causados ao balanço de pagamentos estão presentes em diversos documentos e publicações oficiais da organização. Serão tratados aqui os efeitos mais relevantes apontados pelo Fundo.

A conceituação da lavagem de dinheiro já foi abordada em tópico específico, todavia é indispensável explicitar os exatos termos pelos quais o Fundo delimita o referido tema.

O branqueamento de capitais refere-se a atividades destinadas a ocultar ou disfarçar as origens do produto do crime (ou seja, "crimes predicados" ou "infrações preconizadas") através de processos que transformam entradas ilegais em resultados aparentemente legítimos. Produtos gerados por crimes como a fraude, o roubo e o tráfico de drogas são feitos para parecerem frutos de atividades honestas - transformados, por exemplo, em contas bancárias legítimas, imóveis, ou bens de luxo. A estreita relação entre o ato criminoso que dá origem aos recursos e seu branqueamento torna muito difícil separar o ato de lavagem de dinheiro do crime subjacente [...] Se não houvesse nenhuma fraude, nenhum crime tributário, nenhum abuso de informação, nenhum tráfico de drogas, nem corrupção, nem mesmo crime gerador de recursos, não haveria lavagem de dinheiro. O branqueamento de capitais é um componente essencial de qualquer geração de lucros do crime, porque sem o branqueamento, o crime não pagaria. (INTERNATIONAL MONETARY FUND - a, 2012, p.4) (Tradução livre) ${ }^{6}$

Trata-se, então, do exercício de um abuso financeiro, capaz de enfraquecer e desequilibrar a estabilidade do balanço de pagamentos, afetando todo o sistema financeiro e econômico de um país. Sendo assim, a lavagem de dinheiro e os crimes à ela relacionados podem afetar a estabilidade econômica por três vias distintas:

\footnotetext{
6 Money laundering refers to activities intended to conceal or disguise the origins of the proceeds of crime (i.e., "predicate crimes" or "predicate offenses") through processes that transform illegal inputs into apparently legitimate outputs. Proceeds generated by crimes such as fraud, theft, and drug trafficking are made to look as if they were the fruits of honest activities - transformed, for instance, into legitimate-looking bank accounts, real estate, or luxury goods. [...] The close relationship between the criminal act that gives rise to proceeds and the laundering of these proceeds makes it very difficult to separate the act of money laundering from the underlying crime. [...] If there were no fraud, no tax crime, no insider trading, no drug trafficking, no corruption, or indeed no proceeds-generating crime at all, there would be no money laundering. Money laundering is an essential component of any profit generating crime, because without the laundering, crime would not pay. (INTERNATIONAL MONETARY FUND a, 2012, p.4)
} 
i) desestabilizando o sistema financeiro do Estado-membro; ii) através da geração de efeitos transfronteiriços, acarretando relevantes problemas a países que não participaram diretamente dos crimes predicados ou lavagem de dinheiro; e iii) através de um efeito adverso na economia global (por exemplo, as transações ilegais não são registradas em estatísticas oficiais e são tão grandes que minam a capacidade dos responsáveis políticos em obter uma imagem verdadeira da situação econômica do país e para formular políticas econômicas coerentes) (INTERNATIONAL MONETARY FUND - a, 2012, p.8) (Tradução livre $)^{7}$.

A atuação do FMI se justificaria não somente em razão da necessidade de auxílio a seus membros, mas também em virtude dos evidentes prejuízos que a lavagem de dinheiro acarreta à economia global. Com relação aos efeitos causados diretamente ao balanço de pagamentos, dois principais merecem destaque:

Impedimento de acesso aos mercados financeiros globais: o fracasso de um membro para lidar eficazmente com a lavagem de dinheiro pode resultar em perda de acesso do seu sistema financeiro aos mercados financeiros globais, com consequências potencialmente negativas para a estabilidade financeira e a economia como um todo. Tornou-se uma prática mais frequente para os supervisores nacionais proibirem seus bancos de lidar com instituições financeiras de países com panoramas normativos e institucionais fracos no combate à lavagem de dinheiro, ou pelo menos, sujeitar as transações com instituições de tais países a condições mais estritas; Desestabilização de entradas e saídas monetárias: as atividades de lavagem de dinheiro podem dar origem a níveis significativos de receitas criminais ou "dinheiro quente" que flui dentro e fora das instituições financeiras individuais de maneiras que são desestabilizadoras para essas instituições. Tais entradas ou saídas podem ser transfronteiriças ou domésticas e, quando as transações em mercados ilegais ou passivos criminais são significativas em relação ao tamanho do setor formal do país, esses fluxos podem afetar todo o sistema financeiro, gerando também potenciais efeitos globais. (INTERNATIONAL MONETARY FUND - a, 2012, p.8-9) (Tradução livre) $)^{8}$

Os crimes predicados ou infrações preconizadas também geram impactos negativos na estabilidade do balanço de pagamentos, merecendo especial atenção, não somente em razão da necessidade de enfrentá-los, mas também como forma de alcançar uma plena compreensão de todo o procedimento em questão. Serão abordados aqui três relevantes crimes predicados, os

7 i) by destabilizing the member's financial system; ii) through important inward or outward spillover effects; and iii) through an adverse effect on the broader economy (e.g., illegal transactions are not recorded in official statistics and are so large as to undermine the ability of economic policymakers to gain a true picture of the state of the economy and to formulate economic policy accordingly). (INTERNATIONAL MONETARY FUND - a, 2012, p.8).

8 Impeded or lost access to global financial markets: The actual or perceived failure of a member to deal effectively with money laundering may result in a loss of access of its financial system to global financial markets, with potentially negative consequences for financial stability and the economy as a whole. It has become a more frequent practice for national supervisors to prohibit their banks from dealing with financial institutions from countries with weak anti-money laundering frameworks, or at least, to subject transactions with institutions from such countries to stricter conditions; Destabilizing inflows and outflows: money laundering activities may give rise to significant levels of criminal proceeds or "hot money" flowing into and out of individual financial institutions in ways that are destabilizing for these institutions. Such inflows or outflows can be either cross-border or domestic and, where transactions in illegal markets or criminal proceeds are significant in relation to the size of the country's formal sector, these flows can affect the entire financial system and have cross-country or potentially global effects. (INTERNATIONAL MONETARY FUND - a, 2012, p.8-9). 
quais recebem especial atenção do Fundo no aconselhamento e desenho de políticas econômicas e monetárias.

i) Fraude do setor financeiro: a lavagem de dinheiro pode estar associada a problemas mais amplos de fraude no setor financeiro. A fraude financeira pode prejudicar o sistema financeiro de um país de diferentes maneiras - através de insolvências bancárias em larga escala que surgem quando os balanços dos bancos não são devidamente valorizados, por grandes saídas de capital do sistema bancário ou pela perda de acesso de um setor financeiro aos mercados financeiros internacionais decorrentes de uma deterioração na reputação da jurisdição; ii) Corrupção: a corrupção gera uma quantidade significativa de receitas que precisam ser lavadas. Suborno, corrupção e questões de governança associadas podem ter impactos diretos e indiretos sobre a estabilidade. $\mathrm{O}$ produto da corrupção é um componente chave dos fluxos financeiros ilícitos que podem criar riscos para a reputação das instituições financeiras receptoras, onde quer que estejam localizadas; iii) Delitos fiscais: a lavagem de dinheiro pode estar associada a uma fraude fiscal que pode prejudicar a situação financeira ou macroeconômica a níveis alarmantes. Uma quantidade significativa de crimes tributários pode afetar o fluxo de receita do governo a um ponto em que seu saldo fiscal é severamente prejudicado. (INTERNATIONAL MONETARY FUND - a, 2012, p.10) (Tradução livre) ${ }^{9}$

Tornam-se claros os desdobramentos econômicos/monetários relacionados à lavagem de dinheiro e, por consequência, a pertinência da atuação do Fundo Monetário Internacional. Partindo desta compreensão, serão analisados os fundamentos normativos nos quais se inserem a atuação do FMI, assim como o desenvolvimento das ferramentas, supervisão e aconselhamento no combate ao branqueamento de capitais e os crimes predicados.

\subsection{O programa de combate à lavagem de dinheiro desenvolvido pelo FMI}

O crescimento vertiginoso das atividades ilícitas e, por consequência, do branqueamento de capitais, chamou a atenção da sociedade internacional, demandando dos agentes globais uma resposta coerente e à altura. Neste escopo o combate à lavagem de dinheiro tornou-se uma das prioridades da agenda global.

O Fundo Monetário Internacional, em razão de sua expertise, poder e influência, também assumiu a tarefa de auxiliar seus membros no combate e repressão do procedimento em questão, tendo por fundamento o seguinte:

9 i) Financial sector fraud: ML may be associated with broader problems of financial sector fraud. The potentially adverse effects on financial stability that may arise from large scale "Ponzi schemes" in the financial sector have been well-publicized. Financial fraud may undermine a country's financial system in many different ways - through large-scale bank insolvencies that ensue when banks' balance sheets are not properly valued, by large outflows of capital from the banking system as the scale of the fraud becomes known, or by the loss of access of a financial sector to international financial markets arising from the deterioration in the jurisdiction's reputation; ii) Corruption: Corruption generates a significant amount of proceeds which need to be laundered. Bribery, corruption, and associated governance issues can have direct and indirect impacts on financial stability. The proceeds of corruption are a key component of illicit financial flows that can create reputational risk for recipient financial institutions, wherever they are located, pose particular threats for offshore financial centers with smaller financial sectors, and result in potentially destabilizing outflows for the source country; iii) Tax crimes: ML may be associated with tax fraud that can undermine financial or macroeconomic activity in important ways. Significant levels of tax crimes may affect the government's revenue stream to a point where its fiscal balance is severely undermined. (INTERNATIONAL MONETARY FUND - a, 2012, p.10).

Revista de Direito Brasileira | São Paulo, SP | v. 19 | n. 8 | p. 122 - 140 |Jan./Abr. 2018 
Essas atividades podem prejudicar a integridade e a estabilidade das instituições e sistemas financeiros, desencorajar o investimento estrangeiro e distorcer os fluxos de capital internacional. Eles podem ter consequências negativas para a estabilidade financeira e o desempenho macroeconômico de um país, resultando em perdas de bem-estar, drenando recursos de atividades econômicas mais produtivas e até mesmo ter efeitos desestabilizadores sobre as economias de outros países. Em um mundo cada vez mais interconectado, os efeitos negativos dessas atividades são globais, e seu impacto na integridade financeira e estabilidade dos países é amplamente reconhecido. Os lavadores de dinheiro e os financiadores do terrorismo exploram tanto a complexidade inerente ao sistema financeiro global como as diferenças entre as leis e sistemas nacionais, sendo especialmente atraídos por jurisdições com controles fracos ou ineficazes onde podem mover seus fundos com mais facilidade sem detecção. Além disso, os problemas em um país podem se espalhar rapidamente para outros países da região ou em outras partes do mundo. (INTERNATIONAL MONETARY FUND - b, 2016, p.1) (Tradução Livre) ${ }^{10}$

No ano 2000 o FMI iniciou suas atividades de supervisão e aconselhamento com foco no combate à lavagem de dinheiro. Estas atividades, em razão do atentado terrorista de Setembro de 2001, tiveram seus objetivos ampliados, passando a abarcar o combate ao financiamento do terrorismo, este intimamente relacionado ao branqueamento de capitais. Em razão do objetivo delimitado para o presente trabalho, não serão abordadas aqui as iniciativas para o combate ao financiamento do terrorismo, mas sim em trabalho próprio a ser desenvolvido.

A principal fundamentação normativa para a atuação do Fundo no tema em questão encontra-se no artigo IV, seção 3, alínea a. Trata-se do tópico mais recorrente no desempenho das atribuições do FMI, a atribuição e permissão de supervisão do sistema monetário internacional.

O Fundo supervisionará o sistema monetário internacional de forma a assegurar sua efetiva operação e supervisionar a conformidade de cada membro com as obrigações previstas na Seção 1 deste artigo. (INTERNATIONAL MONETARY FUND - c, 2016, p.6) (Tradução Livre) ${ }^{11}$

O panorama de combate à lavagem de dinheiro dos Estados-membros do FMI engloba tanto as políticas domésticas quanto externas, ambas enquadradas nas obrigações estabelecidas pelo artigo IV, Seção 1. De natureza interna exemplifica-se o controle de operações domésticas dentro do sistema bancário do país (transferência de saldos entre titulares de contas residentes em dois bancos domésticos). Como exemplo de política externa têm-se as regras que regem a realização de pagamentos e transferências de recursos financeiros para instituições no exterior, as quais produzem efeitos transnacionais ou potencialmente globais (INTERNATIONAL

10 These activities can undermine the integrity and stability of financial institutions and systems, discourage foreign investment, and distort international capital flows. They may have negative consequences for a country's financial stability and macroeconomic performance, resulting in welfare losses, draining resources from more productive economic activities, and even have destabilizing spillover effects on the economies of other countries. In an increasingly interconnected world, the negative effects of these activities are global, and their impact on the financial integrity and stability of countries is widely recognized. Money launderers and terrorist financiers exploit both the complexity inherent in the global financial system as well as differences between national AML/CFT laws and systems, and they are especially attracted to jurisdictions with weak or ineffective controls where they can more easily move their funds without detection. Moreover, problems in one country can quickly spread to other countries in the region or in other parts of the world. (INTERNATIONAL MONETARY FUND - b, 2016, p.1).

11 The Fund shall oversee the international monetary system in order to ensure its effective operation, and shall oversee the compliance of each member with its obligations under Section 1 of this Article. (INTERNATIONAL MONETARY FUND - c, 2016, p.6). 
MONETARY FUND - a, 2012, p.7). Trata-se, então, de um chamado para atuação conjunta e conectada, envolvendo o Fundo e seus membros, tanto na esfera doméstica quanto global.

Estabelecido o panorama normativo, o qual prevê e fundamenta com clareza a possibilidade e necessidade de atuação do FMI, passa-se agora à análise dos mecanismos e iniciativas utilizados para o combate e repressão da lavagem de dinheiro e crimes predicados.

Nos últimos 17 anos, os esforços do FMI nesta área ajudaram a moldar nacional e internacionalmente, políticas de combate à lavagem de dinheiro. Foram realizadas mais de 70 avaliações, múltiplos envolvimentos em Consultas do Artigo IV, Programas de Avaliação do Setor Financeiro (FSAPs - Financial Sector Assessment Programs), além de investimentos na concepção e implementação de medidas relacionadas à integridade financeira em programas apoiados pelo Fundo. Foram também desenvolvidas diversas atividades de desenvolvimento em capacitação e projetos de pesquisa. A ampla experiência do FMI no exercício de vigilância e supervisão sobre os sistemas econômicos dos membros permitiu também a condução de avaliações do setor financeiro e desenvolvimento de capacidade técnica para seus países membros. Por fim, o Fundo foi particularmente útil no fornecimento de conselhos de integridade financeira, avaliando a conformidade dos países com os padrões internacionais de combate à lavagem de dinheiro. (INTERNATIONAL MONETARY FUND - b, 2016, p.2).

Em consonância com o crescente reconhecimento da importância das questões de integridade financeira para o FMI, o programa de combate à lavagem de dinheiro evoluiu ao longo dos anos. Em 2004, o Conselho Executivo concordou em incluir as avaliações de combate ao branqueamento de capitais e as atividades de capacitação como parte regular do trabalho do FMI. Em Junho de 2011, o Conselho Executivo discutiu um relatório revisando a evolução do programa e forneceu orientação sobre como avançar nesta área. Os principais resultados da discussão incluem, notadamente, o endosso para abordar questões de integridade financeira na vigilância de forma obrigatória pelo Fundo. (INTERNATIONAL MONETARY FUND - b, 2016, p.2).

O desenvolvimento das atividades referidas, assim como o avanço e aperfeiçoamento do programa de combate à lavagem de dinheiro, demonstrou ser extremamente complexo e refinado, apresentando claros sinais de ampliação e efetividade. Tais constatações elevam o Fundo a um patamar de elevada importância no combate ao branqueamento de capitais, patamar este compatível com o papel que desempenha na economia global.

\subsection{Pontos positivos da atuação do FMI}

Após dezessete anos de desenvolvimento e aprimoramento o combate à lavagem de dinheiro, o FMI demonstrou ter colaborado sobremaneira com a temática, tendo auxiliado diversos de seus membros e, por consequência, o equilíbrio e saúde da economia global.

Entre os diversos avanços e qualidades da atuação do Fundo, é indispensável salientar oito delas: $I$ - Abertura para a investigação independente de suas práticas; $I I$ - Vontade de fazer perguntas básicas sobre os objetivos e a eficácia dos regimes de combate à lavagem de dinheiro; $I I I$ - Compromisso com a experimentação em técnicas de avaliação; $I V$ - Impulso para esclarecer metas e objetivos; $V$ - Liderança no impulso das avaliações para avaliar se os resultados efetivos resultaram da implementação de padrões; VI - investimento em equipes de avaliação experientes altamente qualificadas; VII - Empreendimentos em iniciativas para encontrar novas formas de dados válidos e confiáveis; VIII - Intenções de estabelecer vínculos mais próximos entre ferramentas específicas de combate à lavagem de dinheiro e problemas direcionados aos sistemas financeiros, por exemplo, evasão fiscal, corrupção e eficácia na obtenção de fundos de doadores para investir em assistência técnica para países que precisam de reformas. (HALLIDAY; LEVI; REUTER, 2014, p.4). 
Torna-se evidente o empenho do Fundo em combater a lavagem de dinheiro e os crimes predicados. Trata-se de um problema extremamente complicado, que, por vezes, esbarra em questões delicadas de políticas e soberania, razão pela qual toda e qualquer iniciativa deve ser bem elaborada. A atuação do Fundo foi condizente com sua função fundacional, razão pela qual deve ser elogiada.

\section{CONCLUSÃO}

A condução do presente trabalho permite, com clareza, concluir a complexidade de todos os procedimentos que circundam a lavagem de dinheiro. A sofisticação e os ardis utilizados pelos criminosos dificultam todas as atuações repressivas. Por esta razão o combate ao branqueamento de capitais deve ser cada vez mais elaborado.

A peça que completa e fortalece este combate é a cooperação internacional, elemento fundamental para o desenvolvimento de quase todas as atividades de um mundo globalizado. Em se tratando de lavagem de dinheiro, a cooperação foi especialmente efetiva, permitindo uma atuação mais ampla e em sintonia entre as diferentes nações do mundo.

Nesta necessidade de cooperação se insere o Fundo Monetário Internacional, que no exercício de suas funções constitutivas desempenha atuação no combate à lavagem de dinheiro há mais de dezessete anos.

A atuação do Fundo, além de ter alcançado resultados significativos, alertou com muita precisão sobre os efeitos da lavagem de dinheiro na economia e nos sistemas monetários domésticos e globais. Este fato despertou a atenção dos agentes globais para situações por vezes ignoradas, estabelecendo a profundidade e a gravidade dos problemas causados pelo branqueamento de capitais.

A conclusão mais evidente é de que a lavagem de dinheiro necessita ser combatida de maneira múltipla, de maneira a abarcar elementos da economia, de política monetária, de cooperação internacional, das ciências penais, entre outros. A gravidade do procedimento e dos crimes que o circundam não pode ser negligenciada, devendo o combate ser tema de elevada importância, tudo a fim de reprimir os ilícitos por vias fundamentalmente efetivas.

\section{REFERÊNCIAS BIBLIOGRAFICAS}

AMBOS, Kai. Lavagem de dinheiro e Direito Penal. Porto Alegre: Sergio Antonio Fabris Editor, 2007.

ANSELMO, Márcio Adriano. Lavagem de dinheiro e cooperação jurídica internacional. São Paulo: Saraiva, 2013.

BADARÓ, Gustavo Henrique; BOTTINI, Pierpaolo Cruz. Lavagem de dinheiro: aspectos penais e processuais penais. 3. ed. São Paulo: Revista dos Tribunais, 2016.

BARROS, Marco Antônio de. Lavagem de dinheiro: implicações penais, processuais e administrativas. São Paulo: Oliveira Mendes, 1998.

COAF. Padrões internacionais de combate à lavagem de dinheiro e ao financiamento do terrorismo e da proliferação: As Recomendações do GAFI: Disponível em: <http://www.coaf.fazenda.gov.br/links-externos/As\%20Recomendacoes\%20GAFI.pdf> Acesso em: 6 de ago de 2017. 
COSTA, Hekelson Bitencourt Viana da. Lavagem de dinheiro: Lei $\mathrm{n}^{\circ}$ 9.613/98. Revista de informação legislativa. vol.38. n. 150. pp. 121-143.abr/jun. Brasília.2001.

HALLIDAY, Terence; LEVI, Michael; REUTER, Peter. Global surveillance of dirty money: assessing assessments of regimes to control money-laundering and combat the financing of terrorism. Center on Law \& Globalization. Illinois. 2014.

INTERNATIONAL MONETARY FUND - a. Anti-money laundering and combating the financing of terrorism inclusion in surveillance and financial stability assessment. Prepared by the Legal Department in consultation with other Departments. Guidance Note. Washington. 2012.

INTERNATIONAL MONETARY FUND - b. The IMF and the fight agaisnt money laundering and the financing of terrorism. Factsheet. Washington. 2016.

INTERNATIONAL MONETARY FUND - c. Articles of Agreement. Washington. 2016. Disponível em : https://www.imf.org/external/pubs/ft/aa/pdf/aa.pdf. Acesso em 22 de Ago de 2017.

MATIAS, Eduardo Felipe. A humanidade e suas fronteiras - do Estado soberano à sociedade global. Rio de Janeiro: Paz e Terra, 2006.

MATSUDA, Rosemeire Kiyoko. Money Laundering in Brazil and in the United States. Disponível em: <https://www2.gwu.edu/ ibi/minerva/Fall2007/Rosemeire.pdf>. Acesso em: 7 de Ago de 2017.

PITOMBO, Antônio Sérgio A. De Moraes. Lavagem de dinheiro: a tipicidade do crime antecedente. São Paulo: Ed. RT, 2003.

PORTELA, Paulo Henrique Gonçalves. Direito Internacional Público e Privado. 9. ed. Salvador: JusPodivm, 2017.

SANCTIS, Fausto Martin de. Crime Organizado e Lavagem de dinheiro: destinação de bens apreendidos, delação premiada e responsabilidade social. 2. ed. São Paulo: Saraiva, 2015.

SILVA, Ricardo Perlingeiro Mendes da Silva. O direito internacional contemporâneo - estudos em homenagem ao professor Jacob Dolinger. Rio de Janeiro: Renovar, 2006.

SOARES, Guido Fernando Silva. Curso de direito internacional público. São Paulo: Atlas, 2002.

SUPERIOR TRIBUNAL DE JUSTIÇA. Informativo 586. Brasília, DF, $1^{\text {o a }} 31$ de julho de 2016. Processo: SEC 10.612-Fl, Relatora Min. Laurita Vaz, julgado em 18/5/2016, Dje 28/6/2016.

WEBER, Richard Weber; JOSEPHE, Lester; KOBOR, Emery; CASSELLA ,Stefan D.; LINN, Courtney J.; FOLEY, Rita Elizabeth; HAMPTON, Alan; ROTH, John. Money Laundering. United States Department of Justice. Executive Office for United States Attorneys. The United States Attorneys' Bulletin. v.5. n.55. Washington. 2007.

ZANCHETTI, Mário. Do crime de "branqueamento" de capitais: Introdução e tipicidade. Coimbra: Almedina, 2001. 